\title{
Clinical observation of two bone cement distribution modes of percutaneous vertebroplasty in the treatment of thoracolumbar Kümmell's disease
}

\author{
Ji-Bin Chen ${ }^{1}$, Ya-Ping Xiao², Dong Chen ${ }^{1}$, Jian-Zhong Chang ${ }^{2}$ and $\mathrm{Te} \mathrm{Li}^{3^{*}}$
}

\begin{abstract}
Background: In recent years, percutaneous vertebroplasty (PVP) has provided a new option for the treatment of Kümmell's disease (KD). This retrospective study aimed to investigate the differences in clinical characteristics, clinical efficacy, and related complications between two types of bone cement distribution patterns in the PVP treatment of $\mathrm{KD}$.

Methods: A total of 63 patients with KD from January 2016 to February 2018 who received PVP treatment were examined at least 24 months. According to $X$-ray distribution modes of bone cement after PVP treatment, they were divided into 2 groups: blocky group (30 cases) and spongy group (33 cases). Clinical features and disease severity preoperatively, and clinical efficacy and related complications postoperatively were statistically compared between the two groups.

Results: The two groups were followed for at least 24 months. The duration of disease, age, Cobb angle, and vertebral compression rate preoperatively were significantly higher in the blocky group than in the spongy group $(P<0.05$, respectively). The height of vertebral anterior margin and BMD were significantly lower in the blocky group than in the spongy group ( $P<0.05$, respectively). The amount of bone cement injected was significantly greater in the blocky group than in the spongy group $(P=0.000)$. VAS and ODI of the two groups were significantly reduced at the first day, the first year, and the last follow-up postoperatively (all $P=0.000$ ) and were maintained at the last follow-up. VAS and ODI postoperatively decreased significantly in the spongy group compared with the blocky group $(P=0.000)$. The correction degrees of kyphosis and vertebral compression postoperatively in the two groups were significantly corrected, but gradually decreased over time $(P<0.05)$, and these correction degrees were significantly higher in the blocky group than in the spongy group, and the postoperative losses were also more serious.

(Continued on next page)
\end{abstract}

\footnotetext{
* Correspondence: 13476174874@139.com

${ }^{3}$ Department of Orthopedic Surgery, General Hospital of Central Theater Command, Wuhan, China

Full list of author information is available at the end of the article
}

(c) The Author(s). 2020 Open Access This article is licensed under a Creative Commons Attribution 4.0 International License, which permits use, sharing, adaptation, distribution and reproduction in any medium or format, as long as you give appropriate credit to the original author(s) and the source, provide a link to the Creative Commons licence, and indicate if changes were made. The images or other third party material in this article are included in the article's Creative Commons licence, unless indicated otherwise in a credit line to the material. If material is not included in the article's Creative Commons licence and your intended use is not permitted by statutory regulation or exceeds the permitted use, you will need to obtain permission directly from the copyright holder. To view a copy of this licence, visit http://creativecommons.org/licenses/by/4.0/ The Creative Commons Public Domain Dedication waiver (http://creativecommons.org/publicdomain/zero/1.0/) applies to the data made available in this article, unless otherwise stated in a credit line to the data. 


\begin{abstract}
(Continued from previous page)
Conclusions: The disease was more serious in the blocky group than in the spongy group. The amount of bone cement, correction degrees of postoperative kyphosis and vertebral compression were significantly higher in the blocky group than in the spongy group, but its postoperative losses of the correction degrees of kyphosis and vertebral compression were also more serious. However, for pain relief and functional recovery, the spongy group was superior to the blocky group. Therefore, the spongy distribution pattern should be formed during the injection of bone cement to obtain better therapeutic effect.
\end{abstract}

Keywords: Kümmell's disease, Osteoporosis, Vertebral compression fracture, Percutaneous vertebroplasty

\section{Background}

Kümmell's disease (KD) is also called avascular necrosis after osteoporotic vertebral compression fractures (OVCFs), post-traumatic vertebral osteonecrosis, vertebral pseudarthrosis, delayed vertebral collapse etc. [1], which is a rare special type of OVCFs [2]. The incidence of KD in OVCFs was reported to be as high as 12.1$42.4 \%[3,4]$. The thoracolumbar vertebra is the most common site of occurrence. The main clinical manifestations are lower back pain and kyphosis [1]. Imaging examination shows the late-onset vertebral collapse and characteristic change of intravertebral vacuum cleft (IVC) or intravertebral vacuum phenomenon (IVP) [5]. IVP often appear as intravertebral radiolucent shadows that are typically band like or linear in shape and are often accompanied by peripheral sclerosis. MRI imaging can find limited fluid filling in the vertebral body [6].

Percutaneous vertebroplasty (PVP) infuses bone cement into the vertebral body in a minimally invasive manner to stabilize the fractured vertebra, provide early relief of lower back pain, restore partial height of the vertebra, and correct kyphosis [7, 8]. PVP treatment can reduce the risk of wedge shape and nerve damage in patients with KD, so early surgical treatment is recommended [9]. According to the different distribution patterns of vertebral bone cement after PVP treatment for $\mathrm{KD}$, it can be divided into two types of bone cement distribution patterns: blocky type and spongy type [10]. The clinical characteristics of different distribution patterns and whether they produce different clinical effects have not been reported.

Therefore, the author used a retrospective method to analyze the patients with single-segment thoracolumbar KD who treated with PVP surgery in our hospitals from January 2016 to February 2018. The clinical characteristics, clinical efficacy, and related complications of the two types of distribution patterns of bone cement were compared to provide a reference for clinical practice.

\section{Methods}

\section{Selection criteria}

This study was a controlled and retrospective study. The patients were blinded, but the researchers were not completely blinded. Inclusion criteria were as follows: (1) patients with single-segment thoracolumbar $\mathrm{KD}$ without new OVCFs in other vertebra; (2) computed tomography $(\mathrm{CT})$ or magnetic resonance imaging (MRI) examination confirmed the existence of IVC. IVC refers to a significant radiolucency (gas containing), which is located centrally or adjacent to the vertebral endplates as seen on CT or plain radiographs. On MRI, according to whether the liquid or gas is full of cracks, the T1weighted image usually shows low signal intensity, while the T2-weighted image shows high or low signal [11]. (3) The "pain vertebra" located in the physical examination was consistent with the imaging examination. (4) Double-energy X-ray determination of bone mineral density (BMD) $T$ value $<-2.5$; (5) bilateral pedicle PVP treatment; (6) follow-up time more than 2 years without fall and other trauma. The exclusion criteria were as follows: (1) patients had severe cardiopulmonary dysfunction, coagulation dysfunction, and other intolerance to surgery; (2) local or systemic infection affected the operation; (3) patients had compression symptoms of nerve root or spinal cord; (5) new OVCFs or KD was found in other vertebral bodies. (6) Obvious compression deformation was found in adjacent vertebra.

\section{General information}

From January 2016 to February 2018, 63 of the 95 patients with KD met the selection criteria and were included in the study, all of whom received PVP treatment (Fig. 1). According to the distribution difference of vertebral bone cement after PVP treatment in the X ray imaging, 63 patients were divided into blocky group (30 cases) and spongy group (33 cases) (Fig. 2). The study was approved by ethics committees of the investigator's hospitals. Written informed consent of clinical data and images was obtained from all patients.

There were no significant differences in gender, damaged segments, visual analog scale (VAS), and Oswestry Disability Index (ODI) preoperatively between the two groups $(P>0.05$, Tables 1 and 2$)$. The duration, age, Cobb angle, and vertebral compression rate of the blocky group were significantly higher than these of the spongy group $(P<0.05$, Table 1$)$. The height of anterior 


\section{Cases of Kümmell 's disease}

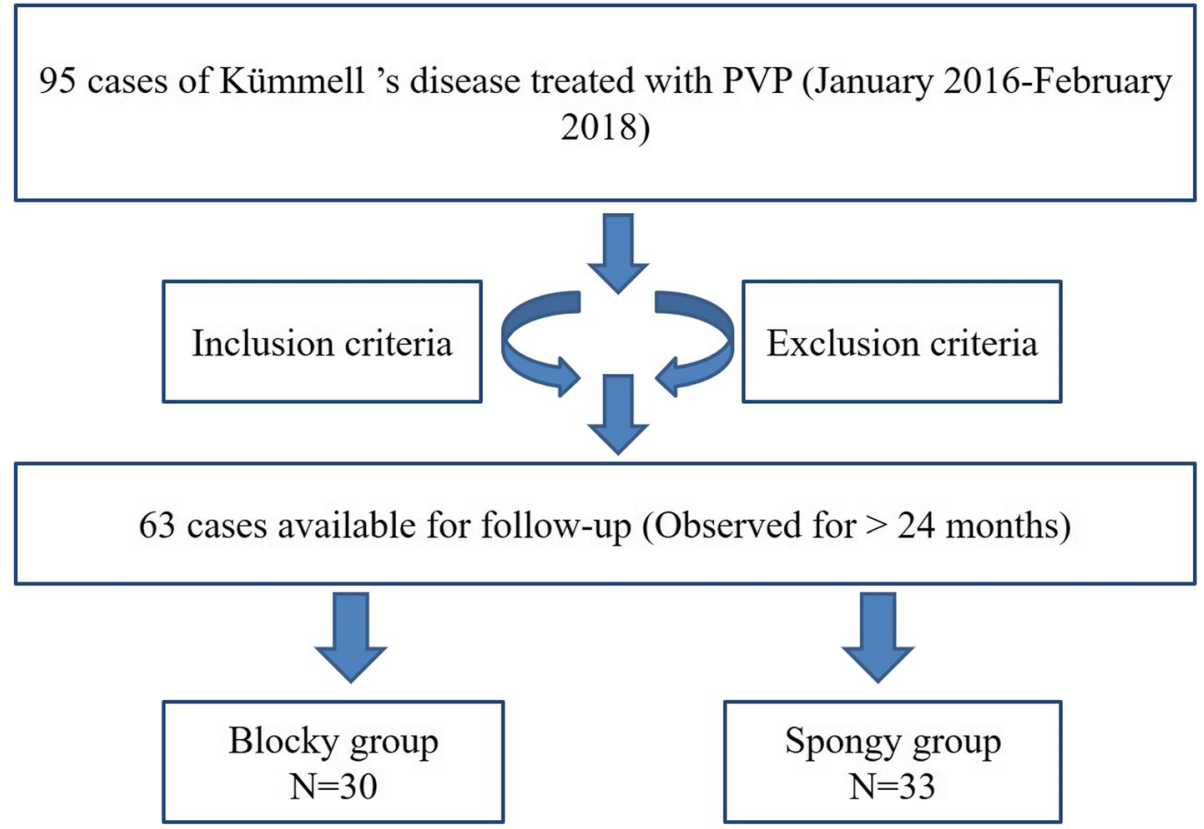

Fig. 1 Cases of Kümmell's disease and follow-up period

vertebral margin and BMD in the blocky group was significantly lower than those in the spongy group $(P<$ 0.05 , respectively, Table 1 ).

\section{Surgical techniques}

All operations were performed by the same group of physicians. The patients lied prone to reposition the spine by extending it. Lidocaine was used for local anesthesia. The injured vertebra was located under Carm X-ray fluoroscopy. The tip of working trocar needle was punctured to the anterior $1 / 3$ of the vertebral body or adjacent to the IVC area through bilateral pedicle approach. Polymethylmethacrylate bone cement (Tecres SPA, Verona, Italy) was injected into the vertebral body or IVC area with a $3.5 \mathrm{~mm}$ side open bone cement injector (Shanghai Kinetic Medical Co., Ltd., Shanghai, China) until the bone cement distribution was well dispersed and satisfactory. The surgical procedures and methods of the two groups were the same and were completed by the same group of surgical staff.

\section{Postoperative treatment}

The patients were kept in the supine position for $24 \mathrm{~h}$ postoperatively. The patients were still on bed rest for 1 month. Lumbar and back support was used to protect the patients from getting off the bed within 1-2 months after surgery. Routine comprehensive anti-osteoporosis treatment postoperatively was conducted by oral administration of calcium carbonate D3 $600 \mathrm{mg} /$ day, alfonetinol tablets $0.5 \mathrm{~g} /$ day, alendronate sodium tablets $10 \mathrm{mg} /$ week) or intravenous infusion of zolefrononic acid (5 $\mathrm{mg} /$ year). X-ray films of injured vertebra were reviewed periodically after surgery.

\section{Efficacy evaluation index}

Intraoperative dispersion morphology, the amount and leakage rate of bone cement, operation time, and the incidence of new adjacent vertebral fracture during the follow-up period were records in the two groups.

Before surgery, at the first day after surgery, the first year after surgery, and the last follow-up, VAS was used to assess the degree of lumbar and back pain of patients [12], and ODI was used to assess the degree of activity limitation of patients [13].

The anterior edge height and Cobb angle of the injured vertebral body were measured on the lateral spine X-ray image before surgery, at the first days after surgery, the first year after surgery, and the last follow-up. According to the data, the following indicators were calculated: (1) rate of vertebral compression is the height of the injured vertebral anterior edge divided by the average height of the adjacent upper and lower vertebral anterior edge [14]. (2) Correction degree of vertebral compression $=$ (the rate of anterior vertebral compression preoperatively-the rate 

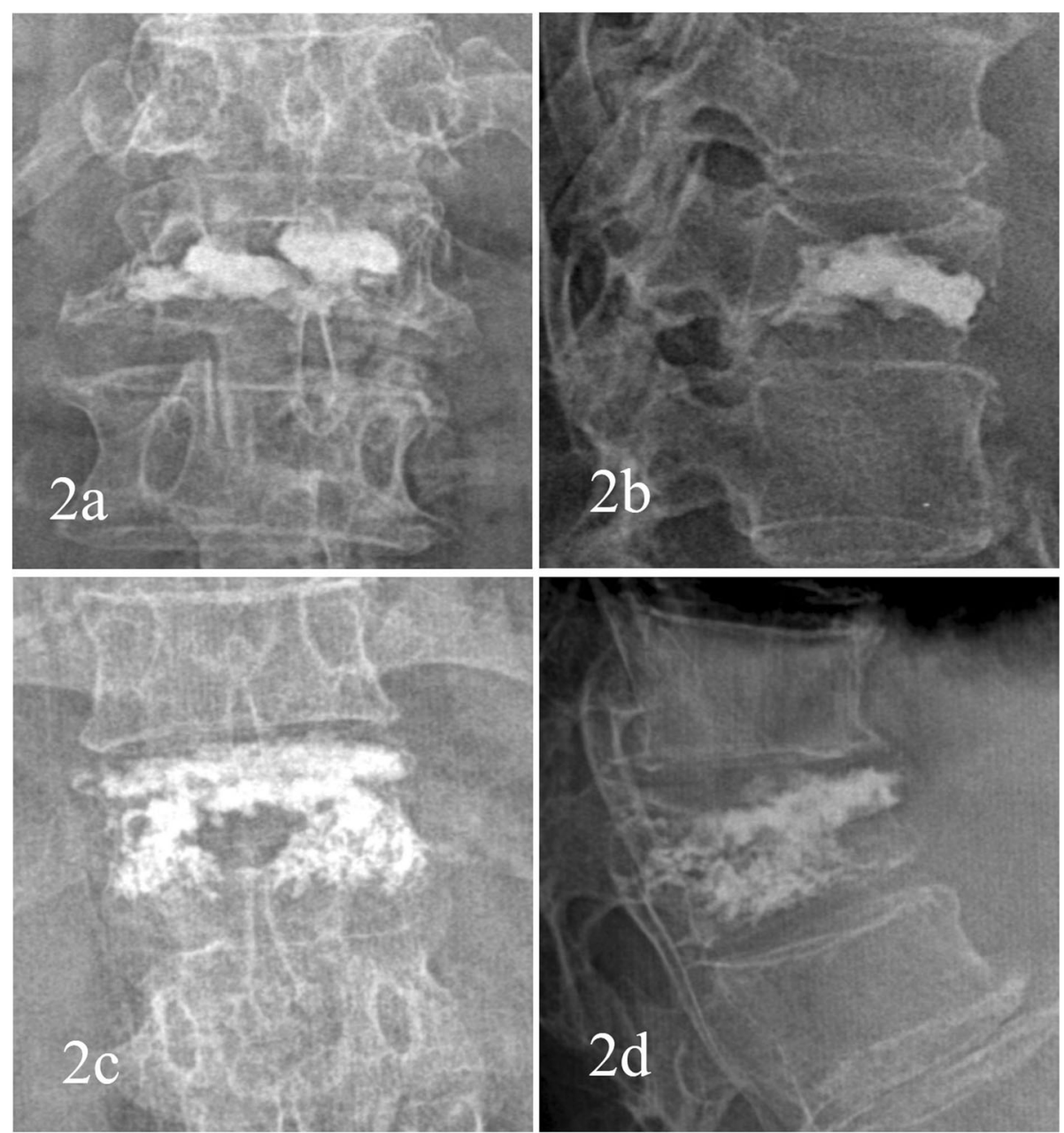

Fig. 2 Distribution characteristics of bone cement. a Anteroposterior X-ray film of local solid distribution pattern in the blocky group. $\mathbf{b}$ Lateral Xray film of local solid distribution pattern in the blocky group. c Anteroposterior X-ray film of diffuse distribution pattern in the spongy group. $\mathbf{d}$ Lateral X-ray film of diffuse distribution pattern in the spongy group

of anterior vertebral compression postoperatively)/the rate of anterior vertebral compression preoperatively $\times \%$ [14]; (3) correction degree of kyphosis $=$ (preoperative Cobb angle - postoperative Cobb angle)/preoperative Cobb angle $\times \%[5]$.

Bone cement leakage was observed after operation. According to the anatomical characteristics of the spine, the leakage sites were classified as intraspinal leakage, anterior vertebral leakage, intervertebral disc leakage, paraspinal vein leakage, and puncture needle leakage.

\section{Statistical analyses}

SPSS19.0 (IBM Corp., Armonk, NY, USA) statistical software was used for statistical analysis. Measurement data were expressed as mean \pm standard deviation. The Levene test was used to test the homogeneity of variance. Independent sample $t$ test was used for intergroup comparison. One-way ANOVA (Bonferroni or
Dunnett T3) was used for comparison between groups at different time points, and repeated measurement analysis of variance was used for intragroup comparison at different time points. The count data were tested by $\chi^{2}$ test. $P<0.05$ was considered statistically different.

\section{Results}

The two groups were followed for at least 24 months. There were no significantly differences in the follow-up time, operation time, intraoperative blood loss, number of fluoroscopy, bone cement leakage, and the incidence of new adjacent vertebral fracture between the two groups (all $P>0.05$ ). The leakage rate of bone cement in the blocky group was $16.67 \%$, including 3 cases of anterior vertebral leakage, 1 case of intervertebral disc leakage, and 1 case of paravertebral vein leakage. The leakage rate of bone cement in the spongy group was $21.21 \%$, including 1 case of anterior vertebral edge 
Table 1 Baseline data of the two groups

\begin{tabular}{|c|c|c|c|c|}
\hline Parameters & Blocky group & Spongy group & $t / x^{2}$ & $P$ \\
\hline Cases & 30 & 33 & & \\
\hline Gender & & & 0.057 & 0.811 \\
\hline Male (cases) & 9 & 9 & & \\
\hline Female (cases) & 21 & 24 & & \\
\hline Age (years) & $76.7 \pm 5.60$ & $73.1 \pm 6.79$ & 19.587 & 0.000 \\
\hline Course of disease (months) & $5.2 \pm 2.34$ & $3.2 \pm 1.35$ & 7.834 & 0.000 \\
\hline Injured vertebral segment & & & 1.271 & 0.736 \\
\hline T11(cases) & 5 & 6 & & \\
\hline T12(cases) & 10 & 13 & & \\
\hline L1(cases) & 12 & 9 & & \\
\hline L2(cases) & 3 & 5 & & \\
\hline BMD ( $T$ value) & $-4.1 \pm 0.91$ & $-3.9 \pm 0.69$ & 2.208 & 0.028 \\
\hline Anterior vertebral height (mm) & $11.0 \pm 4.19$ & $11.7 \pm 3.80$ & -2.292 & 0.022 \\
\hline Cobb angle $\left(^{\circ}\right)$ & $13.2 \pm 4.78$ & $12.5 \pm 4.08$ & 2.199 & 0.028 \\
\hline Vertebral compression rate(\%) & $35.4 \pm 8.99$ & $34.2 \pm 8.84$ & 2.953 & 0.003 \\
\hline
\end{tabular}

leakage, 3 cases of intervertebral disc leakage and 3 cases of paravertebral vein leakage. However, there were no related clinical symptoms in the both groups. The amount of bone cement injected into the blocky group was significantly higher than that of the spongy group $(P$ $=0.000)($ Table 2$)$.

VAS and ODI postoperatively of the two groups were significantly reduced at all time points (all $P=0.000$ ) and were maintained at the last follow-up. VAS and ODI postoperatively decreased significantly in the spongy group compared with the blocky group at all time points (all $P=0.000$ ) (Table 2).

The correction degrees of kyphosis and vertebral compression postoperatively in the two groups were significantly corrected, but gradually decreased over time $(P<0.05)$, and these correction rates of the blocky group were significantly higher than these of the spongy group, and the postoperative losses over time were also more serious (loss rate of correction degree of kyphosis at last follow-up $18.25 \%$ vs. $10.65 \%$; loss rate of correction degree of vertebral compression $16.34 \%$ vs. $7.35 \%$ ) (Table 2 ).

\section{Discussion}

Since Galiber et al. [15] applied PVP in the treatment of 1 case of C2 vertebral invasive hemangioma in 1984, PVP has gradually become one of the effective methods for the treatment of vertebral tumor and OVCFs due to its advantages of simple operation and definite efficacy $[12,16,17]$. KD is a rare special type in OVCFs. After minor trauma, vertebral collapse and kyphosis gradually appear, which are related to vertebral ischemia and necrosis and the formation of vertebral pseudarthrosis.
The occurrence of KD is usually manifested as intractable lumbago and back pain, and in severe cases, nerve damage may occur $[18,19]$. X-ray and CT examination shows IVC in the vertebral body, and MRI suggests limited fluid filling in the vertebral body $[1,2,20]$. IVC is mainly located in the thoracolumbar region, and most of the fractures are wedge-shaped fractures, with fractures occurring near the upper and lower endplates of the vertebral body [11, 21].

Due to the presence of IVC and pseudarthrosis, the injured vertebra of $\mathrm{KD}$ can flex during spinal flexion activities, which can widen the cracks in the vertebral body [22]. The partial correction of collapsed vertebral height and kyphosis can be achieved when the spine is extended. In PVP treatment, the bone cement is often confined to the diffusion in the crack, which has the effect of maintaining the extension and correcting kyphosis, without the need of PKP balloon expansion and reduction. Spontaneous reduction can occur in patients with $\mathrm{KD}$ in posterior extension without further balloon expansion reduction [23, 24]. Heo et al. [25] reported that excessive reduction is likely to accelerate the process of vertebral ischemia and necrosis, leading to severe recollapse, so excessive reduction of injured vertebra during surgery should be avoided. PKP has no obvious clinical advantages over PVP [25]. Therefore, we selected PVP combined with postural reduction to treat KD.

A small dose of bone cement can restore the mechanical properties of the fractured vertebral body, and the amount of bone cement injected has no obvious correlation with the analgesic effect [26, 27]. Even $1.5 \mathrm{ml}$ of bone cement injected into each vertebral body can 
Table 2 Comparison of clinical outcomes between the two groups

\begin{tabular}{|c|c|c|c|c|}
\hline Parameters & Blocky group & Spongy group & $t / x^{2}$ & $P$ \\
\hline Follow-up time(months) & $37.6 \pm 6.59$ & $37.6 \pm 6.86$ & -0.077 & 0.939 \\
\hline Amount of bone cement injected(ml) & $4.7 \pm 1.55$ & $4.0 \pm 1.16$ & 3.897 & 0.000 \\
\hline Operation time (min) & $38.9 \pm 5.52$ & $38.7 \pm 5.05$ & 0.864 & 0.388 \\
\hline Intraoperative blood loss (ml) & $20.8 \pm 2.94$ & $20.7 \pm 3.39$ & 0.438 & 0.661 \\
\hline Fluoroscopy times & $18.1 \pm 2.85$ & $18.1 \pm 3.31$ & -0.237 & 0.813 \\
\hline Bone cement leakage(\%) & 16.67 & 21.21 & 0.211 & 0.646 \\
\hline Yes (cases) & 5 & 7 & & \\
\hline No (cases) & 25 & 26 & & \\
\hline \multicolumn{5}{|l|}{ VAS } \\
\hline Before surgery & $8.2 \pm 1.43$ & $7.9 \pm 1.72$ & 1.646 & 0.100 \\
\hline On the first day after surgery & $3.1 \pm 0.92^{*}$ & $2.4 \pm 0.66^{*}$ & 5.401 & 0.000 \\
\hline At the first year after surgery & $3.5 \pm 0.88^{*}$ & $2.6 \pm 0.82^{*}$ & 6.508 & 0.000 \\
\hline At the last follow-up & $3.6 \pm 0.88^{*}$ & $2.8 \pm 0.80^{*}$ & 7.031 & 0.000 \\
\hline \multicolumn{5}{|l|}{ ODI } \\
\hline Before surgery & $72.6 \pm 10.89$ & $70.5 \pm 10.03$ & 5.293 & 0.162 \\
\hline On the first day after surgery & $29.4 \pm 5.42^{*}$ & $24.4 \pm 5.13^{*}$ & 24.533 & 0.000 \\
\hline At the first year after surgery & $29.8 \pm 5.39^{*}$ & $24.9 \pm 5.01^{*}$ & 25.407 & 0.000 \\
\hline At the last follow-up & $29.9 \pm 5.41^{*}$ & $25.0 \pm 5.56^{*}$ & 22.872 & 0.000 \\
\hline Adjacent vertebral fractures(\%) & 16.67 & 9.09 & 0.814 & 0.367 \\
\hline Yes (cases) & 5 & 3 & & \\
\hline No (cases) & 25 & 30 & & \\
\hline \multicolumn{5}{|c|}{ Correction degree of vertebral compression } \\
\hline On the first day after operation & $25.7 \pm 4.28$ & $20.4 \pm 4.70$ & 21.962 & 0.000 \\
\hline At the first year after operation & $22.8 \pm 4.92 \#$ & $19.6 \pm 3.63$ & 13.281 & 0.000 \\
\hline At the last follow-up & $21.5 \pm 4.29 \& @$ & $18.9 \pm 3.47 \#$ & 11.952 & 0.000 \\
\hline \multicolumn{5}{|l|}{ Correction degree of kyphosis } \\
\hline On the first day after operation & $26.3 \pm 5.34$ & $21.6 \pm 5.69$ & 22.467 & 0.000 \\
\hline At the first year after operation & $23.4 \pm 5.24 \#$ & $20.1 \pm 5.26 \#$ & 17.093 & 0.000 \\
\hline At the last follow-up & $21.5 \pm 5.17 \& @$ & $19.3 \pm 5.19 \&$ & 14.509 & 0.001 \\
\hline
\end{tabular}

${ }^{*}$ Compared to before surgery, $P=0.000$

"Compared to the first day after operation, $P<0.05$

${ }^{\&}$ Compared to the first day after operation, $P=0.000$

${ }^{\circledR}$ Compared to the first year after operation, $P<0.05$

obtain satisfactory analgesic effect $[26,27]$. Biomechanical studies have confirmed that vertebral strength can be restored by injecting about $2 \mathrm{ml}$ bone cement, and vertebral stiffness can be restored by injecting about 4 $\mathrm{ml}$ bone cement [27]. In this study, both groups have reached the requirements of restoring vertebral strength and stiffness. However, the amount of bone cement injected is a one-sided index to reflect the benefit of bone cement and cannot reflect the distribution of bone cement in vertebral body. The diffusion volume of bone cement can more reasonably reflect the distribution of bone cement in vertebral body. This study suggests that different distribution patterns of bone cement are closely related to the degree of osteoporosis, the degree of compression, the position and internal morphology of IVC, and the degree of peripheral sclerosis of IVC.

In this study, VAS and ODI postoperatively were significantly reduced in both groups and were maintained to the last follow-up. Li et al. [28] found that VAS and ODI were significantly improved at the last follow-up compared with those before treatment in patients with KD after intensive vertebral treatment. In this study, spongy group is superior to the blocky group in terms of pain relief and functional recovery. Due to the obstruction of the ossification band and fibrous membrane at the edge of IVC, bone cement of the blocky group was filled in the IVC region in the form of solid mass, resulting in the failure of effectively filling of bone cement in 
other gaps and osteoporosis areas around the crack. The limited bone cement mass cannot be connected with the upper and lower adjacent endplates and cannot strengthen cancellous bone of vertebrae, which is more prone to stress shielding leading to recollapse [29], and cannot support the normal physiological stress from the body resulting in the continued existence of pain symptoms caused by osteoporosis [30]. In the spongy group, the bone cement was intercalated trabeculae with diffuse distribution and had high degree of vertebral strengthening. In this study, the average injected amount of bone cement per vertebra in the blocky group was $4.7 \pm 1.55$ $\mathrm{ml}$ vs. $4.0 \pm 1.16 \mathrm{ml}$ in the spongy group. Although the injected amount was more in the blocky group than in the spongy group, the spongy group showed better recovery of pain relief and function after treatment. Many scholars also found that the injected amount of bone cement was not proportional to the analgesic effect $[26,27]$. Therefore, it is suggested that the fractured cracks should be filled and the cement should be better distributed in the vertebrae in the PVP treatment. We found that the postoperative correction degrees of vertebral compression and kyphosis in the two groups gradually decreased over time, suggesting that the postoperative vertebral height and Cobb angle gradually lost, which was consistent with previous findings [17, 31]. The loss of the blocky group was more obvious than that of the spongy group, which was related to the distribution pattern of the bone cement itself.

The correction rate of postoperative kyphosis and vertebral compression was more obvious in both groups, but these correction rates of blocky group were more obvious than that of spongy group. Course of the disease, age, preoperative Cobb angle, and vertebral compression rate of the blocky group were significantly higher than those of the spongy group, while the anterior vertebral height and BMD of the blocky group were significantly lower than those of the spongy group. It is suggested that the condition of $\mathrm{KD}$ in the blocky group is more serious than that of the spongy group. So the formation time of IVC is longer, the volume of IVC is larger, and the pseudarthrosis is obvious. Therefore, when the spine is in the position of posterior extension, the vertebral body has a large reduction space and presents the "open-mouth state." The injected bone cement presents a mass distribution, which effectively restore the height of vertebral body and correct kyphosis.

The bone cement leakage rate of the blocky group was $16.67 \%$ lower than that of the sponge group (21.21\%), but there was no statistical difference between the two groups. Krauss et al. [32] reported that the bone cement leakage rate was $18.2 \%$ in the PVP treatment of $\mathrm{KD}$. Wang et al. [33] reported that the bone cement leakage rate was $7.4 \%$ in the PKP treatment of KD. In the blocky group, the anterior vertebral edge leakage was the main part, while in the spongy group, the intervertebral disc leakage and the paravertebral vein leakage were the main part. However, there were no related clinical symptoms in both groups. In the blocky group, due to the obstruction of the sclerosis band and fibrous membrane around the IVC area, the injection of bone cement showed a lumped distribution. The bone cortex in the anterior edge of the vertebral body was often incomplete, which could leak out along the anterior edge to the front of the vertebral body. Therefore, the incidence of leakage in the anterior edge of the vertebral body of the blocky group was the highest. However, the spongy group of bone cement was widely inserted into the trabecular space and distributed in a diffuse manner, which was easy to be squeezed into the intervertebral disc and the paravertebral vein plexus. In order to prevent the occurrence of bone cement leakage, the operator should carefully analyze the imaging data before treatment, fully understand the IVC position, size and fracture site, and grasp the position of pedicle injection.

The blocky group had an incidence of adjacent vertebral fracture of $16.67 \%$ vs. the spongy group of $9.09 \%$. But there was no statistical difference between the two groups. It indicates that the blocky distribution of bone cement is more likely to lead to the occurrence of adjacent vertebral fractures. Yang et al. [34] found that 14.139.1\% OVCFs patients in the PVP treatment experienced an adjacent vertebral fractures during the first year after surgery. In the blocky group, the vertebral body was seriously compressed and kyphosis was obvious. The biomechanics of adjacent segments changed greatly. The mechanical transfer between the vertebral body and the intervertebral disc was changed, resulting in the increase of the stress of adjacent vertebrae and the higher probability of new refracture. In addition, the bone cement was filled in the IVC area in the form of solid mass, which was more prone to stress shielding, increased the stress load of adjacent intervertebral discs and vertebral bodies, and increased the risk of recurrent fractures [29]. The bone cement in the spongy group was evenly distributed, which made the stress of the whole vertebral body relatively evenly distributed, and reduced the concentrated stress on the adjacent vertebral body and intervertebral disc. Therefore, the complication rate of new adjacent vertebral fracture is low.

This study has some limitations. Firstly, KD is relatively rare and easy to be complicated with OVCFs and multiple fractures, so there are few cases to meet the inclusion criteria. Therefore, the number of cases in this study was small, and the sample size needs to be expanded for further verification and analysis. Preoperative ICV morphology and size were not measured in three dimensions. Biomechanical studies of cement distribution in the 
vertebrae on adjacent vertebral bodies and intervertebral discs were lacking to support the results. The researchers were not completely blinded in the collection of data, which may lead to bias in the data. Therefore, the current findings provide a clinical reference, but need to be validated in further multi-center, randomized, double-blind clinical trials.

\section{Conclusions}

PVP can effectively relieve pain, improve function, restore vertebral height, and correct kyphosis in the treatment of KD. Compared with the spongy group, the blocky group had longer course, older age, and more serious kyphosis, vertebral compression, and osteoporosis. The amount of bone cement injected into the blocky group was significantly higher than that of the spongy group. Furthermore, the correction degrees of kyphosis and vertebral compression in the blocky group were more obvious than these in the spongy group, but the postoperative losses were also more serious. However, VAS and ODI were significantly lower in the spongy group than in the blocky group. Therefore, the spongy distribution pattern should be formed during the injection of bone cement to obtain better therapeutic effect.

\section{Abbreviations \\ PVP: Percutaneous vertebroplasty; PKP: Percutaneous kyphoplasty; OVCFs: Osteoporotic vertebral compression fractures; IVC: Intravertebral vacuum cleft; ODI: Oswestry Disability Index; VAS: Visual analog scale; IVP: Intravertebral vacuum phenomenon; BMD: Bone mineral density}

\section{Acknowledgements}

We wish to thank radiology department, physical medicine, other orthopedic medical staff and rehabilitation nurse, for her help and cooperation during the study. In particular, we would like to thank Cheng-Liang Wang for his assistance in paper design, original data collection, and paper writing.

\section{Authors' contributions}

All authors made substantive intellectual contributions in this study to qualify as authors. $C$ JB and $L T$ designed this study. C JB, X YP, C D, and C JB participated in collecting and analyzing raw materials. An initial draft of the manuscript was written by $C J B$ and X YP. C D, C JB, and L T re-drafted parts of the manuscript and provided helpful advice on the final revision. All authors were involved in writing the manuscript. All authors read and approved the final manuscript.

\section{Funding}

There is no funding for the current study.

\section{Availability of data and materials}

The datasets used and/or analyzed during the current study are available from the corresponding author on reasonable request.

\section{Ethics approval and consent to participate}

This study was approved by the institutional review boards/Ethics Committees of Wuhan Hanyang Hospital and General Hospital of Central Theater Command, and was conducted in compliance with the ethical principles of the Helsinki Declaration of 1975. Written informed consent was obtained from the patients or their family members.

\section{Consent for publication}

Not applicable.

\section{Competing interests}

No potential conflict of interest relevant to this article was reported.

\section{Author details}

'Department of Orthopedics, Wuhan Hanyang Hospital, Wuhan University of Science and Technology, Wuhan 430050, China. ${ }^{2}$ Department of Orthopedic Surgery, CR \& WISCO General Hospital, Wuhan University of Science and Technology, Wuhan, China. ${ }^{3}$ Department of Orthopedic Surgery, General Hospital of Central Theater Command, Wuhan, China.

Received: 11 April 2020 Accepted: 30 June 2020

Published online: 09 July 2020

\section{References}

1. He D, Yu W, Chen Z, et al. Pathogenesis of the intravertebral vacuum of Kümmell's disease. Exp Ther Med. 2016;12(2):879-82.

2. Lim J, Choi S-W, Youm J-Y, et al. Posttraumatic delayed vertebral collapse Kummell's disease. J Korean Neurosurg Soc. 2018;61(1):1-9.

3. Fang $X, Y u$ F, Fu S, et al. Intravertebral clefts in osteoporotic compression fractures of the spine: incidence, characteristics, and therapeutic efficacy. Int J Clin Exp Med. 2015;8(9):16960-8.

4. Wu AM, Lin ZK, Ni WF, et al. The existence of intravertebral cleft impact on outcomes of nonacute osteoporotic vertebral compression fractures patients treated by percutaneous kyphoplasty: a comparative study. J Spinal Disord Tech. 2014;27(3):E88-93.

5. Jiang J, Gu F-L, Li Z-W, et al. The clinical efficacy and experience of bipedicular percutaneous vertebroplasty combined with postural reduction in the treatment of Kümmell's disease. BMC Musculoskelet Disord. 2020; 21(1):82.

6. Feng S-W, Chang M-C, Wu H-T, et al. Are intravertebral vacuum phenomena benign lesions? Eur Spine J. 2011;20(8):1341-8.

7. Zuo X-H, Zhu X-P, Bao H-G, et al. Network meta-analysis of percutaneous vertebroplasty, percutaneous kyphoplasty, nerve block, and conservative treatment for nonsurgery options of acute/subacute and chronic osteoporotic vertebral compression fractures (OVCFs) in short-term and long-term effects. Medicine. 2018;97(29):e11544.

8. Zhang $\mathrm{H}, \mathrm{Xu} \mathrm{C}$, Zhang $\mathrm{T}$, et al. Does percutaneous Vertebroplasty or balloon Kyphoplasty for osteoporotic vertebral compression fractures increase the incidence of new vertebral fractures? A meta-analysis. Pain Physician. 2017; 20(1):E13-28.

9. Li H, Liang CZ, Chen QX. Kümmell's disease, an uncommon and complicated spinal disorder: a review. J Int Med Res. 2012;40(2):406-14.

10. Tanigawa N, Komemushi A, Kariya S, et al. Relationship between cement distribution pattern and new compression fracture after percutaneous vertebroplasty. AJR Am J Roentgenol. 2007;189(6):W348-52.

11. Yu W, Liang D, Yao Z, Qiu T, et al. The therapeutic effect of intravertebral vacuum cleft with osteoporotic vertebral compression fractures: a systematic review and meta-analysis. Int J Surg. 2017:40:17-23.

12. Khan M, Kushchayev SV. Percutaneous vertebral body augmentations: the state of art. Neuroimaging Clin N Am. 2019;29(4):495-13.

13. Zhang $Y$, Shi L, Tang P, Zhang L. Comparison of the efficacy between two microoperative therapies of old patients with osteoporotic vertebral compression fracture: a network meta-analysis. J Cell Biochem. 2017;118(10):3205-12.

14. Chen C, Fan P, Xie X, Wang Y, et al. Clin Spine Surg. 2020. https://doi.org/10 1097/BSD.0000000000000928.

15. Galibert $P$, Deramond $H$, Rosat $P$, et al. Preliminary note on the treatment of vertebral angioma by percutaneous acrylic vertebroplasty. Neurochirurgie. 1987;33(2):166-8.

16. Dydyk AM, M Das J. Vertebral Augmentation. In: StatPearls. edn. Treasure Island (FL): StatPearls Publishing; 2020.

17. Huang S, Zhu X, Xiao D, Zhuang J, et al. Therapeutic effect of percutaneous kyphoplasty combined with anti-osteoporosis drug on postmenopausal women with osteoporotic vertebral compression fracture and analysis of postoperative bone cement leakage risk factors: a retrospective cohort study. J Orthop Surg Res. 2019;14(1):452.

18. Liu F, Chen Z, Lou C, et al. Anterior reconstruction versus posterior osteotomy in treating Kümmell's disease with neurological deficits: a systematic review. Acta Orthop Traumatol Turc. 2018;52(4):283-8.

19. Huang Y-S, Hao D-J, Wang X-D, et al. Long-segment or bone cementaugmented short-segment fixation for Kummell disease with neurologic deficits? A comparative cohort study. World Neurosurg. 2018;116:e1079-e86. 
20. D'Oria S, Delvecchio C, Dibenedetto M, et al. Case report of Kummell's disease with delayed onset myelopathy and the literature review. Eur J Orthop Surg Traumatol. 2018;28(2):309-16.

21. Kim H, Jun S, Park SK, et al. Intravertebral vacuum cleft sign: a cause of vertebral cold defect on bone scan. Skelet Radiol. 2016;45(5):707-12.

22. Lu W, Wang L, Xie C, et al. Analysis of percutaneous kyphoplasty or shortsegmental fixation combined with vertebroplasty in the treatment of Kummell disease. J Orthop Surg Res. 2019;14(1):311.

23. Hur W, Choi SS, Lee M, et al. Spontaneous vertebral reduction during the procedure of Kyphoplasty in a patient with Kummell's disease. Korean J Pain. 2011;24(4):231-4.

24. Hur W, Lee JJ, Kim J, et al. Spontaneous air reduction of vertebra plana with Kummell's disease during vertebroplasty: subsequent experience with an intentional trial. Pain Med. 2014;15(7):1240-2.

25. Chang JZ, Bei MJ, Shu DP, et al. Comparison of the clinical outcomes of percutaneous vertebroplasty vs. kyphoplasty for the treatment of osteoporotic Kummell's disease:a prospective cohort study. BMC Musculoskelet Disord. 2020; 21(1):238.

26. Molloy S, Mathis JM, Belkoff SM. The effect of vertebral body percentage fill on mechanical behavior during percutaneous vertebroplasty. Spine. 2003; 28(14):1549-54.

27. Graham J, Ahn C, Hai N, Buch BD. Effect of bone density on vertebral strength and stiffness after percutaneous vertebroplasty. Spine. 2007;32(18): E505-E11.

28. Li Z, Liu T, Yin P, Wang Y, et al. The therapeutic effects of percutaneous kyphoplasty on osteoporotic vertebral compression fractures with or without intravertebral cleft. Int Orthop. 2019;43(2):359-65.

29. Niu J, Zhou H, Meng Q, et al. Factors affecting recompression of augmented vertebrae after successful percutaneous balloon kyphoplasty: a retrospective analysis. Acta Radiol. 2015;56(11):1380-7.

30. Kim Y-Y, Rhyu K-W. Recompression of vertebral body after balloon kyphoplasty for osteoporotic vertebral compression fracture. Eur Spine J. 2010;19(11):1907-12.

31. Patel A, Carter KR. Percutaneous Vertebroplasty And Kyphoplasty. In: StatPearls. edn. Treasure Island (FL): StatPearls Publishing; 2020.

32. Krauss M, Hirschfelder $H$, Tomandl B, et al. Kyphosis reduction and the rate of cement leaks after vertebroplasty of intravertebral clefts. Eur Radiol. 2006; 16(5):1015-21.

33. Wang G, Yang H, Chen K. Osteoporotic vertebral compression fractures with an intravertebral cleft treated by percutaneous balloon kyphoplasty. J Bone Joint Surg Br. 2010;92(11):1553-7.

34. Yang C-C, Chien J-T, Tsai T-Y, et al. Earlier Vertebroplasty for osteoporotic thoracolumbar compression fracture may minimize the subsequent development of adjacent fractures: a retrospective study. Pain Physician. 2018;21(5):E483-E91.

\section{Publisher's Note}

Springer Nature remains neutral with regard to jurisdictional claims in published maps and institutional affiliations.

Ready to submit your research? Choose BMC and benefit from:

- fast, convenient online submission

- thorough peer review by experienced researchers in your field

- rapid publication on acceptance

- support for research data, including large and complex data types

- gold Open Access which fosters wider collaboration and increased citations

- maximum visibility for your research: over $100 \mathrm{M}$ website views per year

At BMC, research is always in progress.

Learn more biomedcentral.com/submissions 